\title{
Importance of Therapeutic Drug Monitoring to Detect Drug Interaction between Pazopanib and Warfarin: A Case Report
}

\author{
Shinya Takasaki ${ }^{1}$, Hisanobu Adachi ${ }^{2}$, Yoshihide Kawasaki ${ }^{2}$, Masafumi Kikuchi ${ }^{1,3}$, Akihiro Ito ${ }^{2}$ and Nariyasu Mano \\ 1,3 \\ 1. Department of Pharmaceutical Sciences, Tohoku University Hospital, Sendai, Miyagi, Japan. 2.Department of Urology, \\ Tohoku University Hospital, Sendai, Miyagi, Japan. ${ }^{3 .}$ Graduate School of Pharmaceutical Sciences, Tohoku University, \\ Sendai, Miyagi Japan.
}

Received, December 5, 2019; Revised, May 2, 2020; Accepted, May 10, 2020; Published, May 10, 2020

\begin{abstract}
Pazopanib is an orally available multi-tyrosine kinase inhibitor and has been used to treat renal cell carcinoma (RCC). Here, we report the case of a patient with RCC with an increased prothrombin timeinternational normalized ratio (PT-INR) due to pazopanib therapy. In addition, we have reported the change in the blood levels of pazopanib. A 75-year-old man underwent a left nephrectomy for RCC. Four years later, his cancer recurred and pazopanib therapy was initiated. He was also taking warfarin for atrial fibrillation and his PT-INR was constant at approximately 2. His warfarin dose was reduced from $3.5 \mathrm{mg} / \mathrm{day}$ to $3.0 \mathrm{mg} / \mathrm{day}$ on day 10 because his PT-INR increased from 2.19 to 3.07 compared to that before starting pazopanib. On day 28, his PT-INR further increased to 4.34 , and his aspartate aminotransferase, alanine transaminase, and alkaline phosphatase levels increased. The target concentration of pazopanib was 20.5 to $50.3 \mu \mathrm{g} / \mathrm{mL}$, but his blood concentrations were $92.1 \mu \mathrm{g} / \mathrm{mL}$ on day 6 and $93.7 \mu \mathrm{g} / \mathrm{mL}$ on day 13. Therefore, both pazopanib and warfarin were discontinued. One week later, his laboratory tests recovered, and hence, warfarin treatment was resumed. However, pazopanib therapy was terminated due to concerns about liver dysfunction. His hepatic dysfunction and increased PT-INR were considered to be due to pazopanib treatment. Pazopanib has been reported to have no effect on the pharmacokinetics of warfarin in clinical patients. In this case, blood levels of pazopanib were abnormally high, possibly causing liver dysfunction and drug interactions, leading to his PT-INR prolongation. TDM monitoring, in addition to the recommended monitoring for pazopanib hepatotoxicity, may help identify patients at risk for drug interactions. For patients receiving concomitant pazopanib and warfarin, close monitoring of PT-INR is warranted.
\end{abstract}

Keywords - TDM, anticancer drug, pazopanib, warfarin, PT-INR, liver dysfunction

\section{INTRODUCTION}

Pazopanib is an orally available multi-tyrosine kinase inhibitor that is used as an anticancer drug for soft tissue sarcoma and renal cell carcinoma (RCC) $(1,2)$. Pazopanib has good anti-tumor effects, but also has various adverse events such as diarrhea, hypertension, fatigue, and liver dysfunction. An especial concern is the hepatic dysfunction caused by pazopanib which often presents and can be severe $(1,2)$, so regular monitoring of liver function test values is essential. Recently, therapeutic drug monitoring (TDM) of these oral anticancer drugs is being used to achieve personalized medicine that maximizes the therapeutic effects while ensuring safe treatment (3-5). The pharmacokinetics/pharmacodynamics (PK/PD) of pazopanib has been analyzed and TDM of pazopanib will begin to be explored (6-8).

TDM has been reported to be useful in discovering drug interactions with oral anticancer agents $(9,10)$. The following are reported as drug interactions related to pazopanib: proton pump inhibitor (PPI) that reduce absorption of pazopanib, and inducers and inhibitors of cytochrome P450 (CYP) 3A4, which is the main metabolic enzyme of pazopanib $(11,12)$. On the other hand, pazopanib has been reported to weakly inhibit CYP3A4 and CYP2D6, and not to affect CYP1A2, CYP2C9, and CYP2C19 (13). $S$-Warfarin, which is responsible for the main effect in the racemic warfarin, is metabolized by CYP2C9, but pazopanib is reported not to affect this enzyme (13).

Herein, we report the case of a patient with RCC with an increased prothrombin time-international normalized ratio (PT-INR), an indicator of warfarin effectiveness, due to pazopanib therapy. In addition,

Corresponding Author: Shinya Takasaki, Department of Pharmaceutical Sciences, Tohoku University Hospital, 1-1 Seiryo-machi, Aoba-ku, Sendai, Miyagi, Japan; E-mail: takasaki_shinya@hosp.tohoku.ac.jp 
by measuring the blood concentration of oral anticancer drugs for personalized treatment of cancer patients, we are able to show the changes in the blood levels of pazopanib in this case.

\section{OBSERVATION}

A 75-year-old man underwent a left nephrectomy for RCC. Four years later, his cancer recurred in right kidney and pazopanib therapy was initiated. In addition, the patient was taking warfarin for atrial fibrillation and has a constant PT-INR of approximately 2. On admission, treatment was started with $400 \mathrm{mg}$ pazopanib once-daily on an empty stomach, but grade 1 leukopenia and thrombocytopenia in Common Terminology Criteria for Adverse Events occurred on day 8 after starting pazopanib therapy. The patient's warfarin dose was reduced from $3.5 \mathrm{mg}$ /day to $3.0 \mathrm{mg} /$ day on day 10 because his PT-INR increased from 2.19 to 3.07 compared to that before starting pazopanib (Figure 1 A). After that, treatment of the patient shifted to the outpatient department. At the outpatient visit on day 28, his PT-INR further increased to 4.34, and his aspartate aminotransferase (AST), alanine transaminase (ALT), and alkaline phosphatase (ALP) levels, which are liver function markers, showed an increase to grade 1 (Figure $1 \mathrm{~B}, \mathrm{C}$ ). In addition, while the target concentration of pazopanib was 20.5 to $50.3 \mu \mathrm{g} / \mathrm{mL}(6,8)$, the patient's blood concentrations were $92.1 \mu \mathrm{g} / \mathrm{mL}$ on day 8 and 93.7 $\mu \mathrm{g} / \mathrm{mL}$ on day 15 (Figure $1 \mathrm{~A}$ ). Therefore, both pazopanib and warfarin were discontinued. After discontinuing pazopanib, his pazopanib blood levels decreased. One week later, the patient's laboratory test values recovered, and his warfarin was resumed. However, pazopanib therapy was subsequently terminated due to concerns about liver dysfunction, and treatment was changed to axitinib, a tyrosine kinase inhibitor. After switching to axitinib, no hepatic dysfunction was observed, and there was no significant change in his PT-INR. Moreover, there was no change in concomitant medications before and after pazopanib treatment.

Measurements of the blood concentration of pazopanib were approved by the Ethics Committee of Tohoku University Graduate School of Medicine (No. 2015-1-866). After obtaining the patient's written informed consent, blood samples were taken immediately before pazopanib administration. The samples were measured using liquid chromatography-tandem mass spectrometry (14). In addition to atrial fibrillation, patient history included hypertension, chronic kidney disease, gastro esophageal reflux disease, and asthma. His concomitant medications were warfarin, valsartan, furosemide, febuxostat, potassium citrate, esomeprazole, pranlukast, inhalant (vilanterol trifenatate, fluticasone furoate), and complex vitamins. His body weight and body mass index at the start of pazopanib treatment were $59.5 \mathrm{~kg}$ and $20.7 \mathrm{~kg} / \mathrm{m}^{2}$, respectively. The results of his laboratory analyses (mean \pm standard deviation) during pazopanib therapy were as follows: total bilirubin $1.3 \pm 0.4 \mathrm{mg} / \mathrm{dL}$, ALP $289 \pm 38 \mathrm{U} / \mathrm{L}$, gamma-glutamyltransferase (GGTP) $26 \pm 7 \mathrm{U} / \mathrm{L}$, AST $38 \pm 15 \mathrm{U} / \mathrm{L}$, ALT $24 \pm 10 \mathrm{U} / \mathrm{L}$, serum creatinine, $1.7 \pm 0.1 \mathrm{mg} / \mathrm{dL}$, uric acid, $6.1 \pm 0.3$ $\mathrm{mg} / \mathrm{dL}$, albumin, $4.2 \pm 0.1 \mathrm{~g} / \mathrm{dL}$.

\section{DISCUSSION}

This is the first case report that pazopanib therapy increased PT-INR in patients taking warfarin and followed changes in the blood concentrations of pazopanib. Based on the administration history of pazopanib and observed changes in liver function tests, hepatic dysfunction and increased PT-INR were, in this case, considered to be due to pazopanib treatment. The patient's pazopanib blood concentrations showed abnormally high levels, and these high levels may have been responsible for this series of adverse events. According to previous reports, polymorphisms in the uridine diphosphate glucuronosyltransferase 1A1 (UGT1A1) gene and the hemochromatosis gene are associated with pazopanib-induced liver damage (15-18). Since we did not examine these genes, pazopanib-induced liver damage may have been associated with gene polymorphisms in this patient. A typical pazopanib dose is usually $800 \mathrm{mg}$ once-daily (2), but his treatment was started at $400 \mathrm{mg}$ once-daily based on medical history (heart and kidney disease). However, his pazopanib blood levels were abnormally high even though the dose was $400 \mathrm{mg}$. Although interindividual variation of pazopanib blood levels is acknowledged $(6,8,19,20)$, there was no obvious reason for his abnormally high levels of pazopanib.

Pharmacokinetics of pazopanib is affected by diet and drug-drug interactions (7, 11, 12, 17, 21). While dietary intake increases absorption of pazopanib, pazopanib administration in this patient was at fasting times $(17,21)$. Esomeprazole, used as a PPI, is known to affect absorption of pazopanib $(11,12,17)$, and this patient was taking it. PPI suppresses acid secretion in the stomach, reduces the solubility of pazopanib, and reduces its absorption $(11,12,17)$, so the PPI he was taking is not responsible for his abnormally high blood levels of pazopanib. 


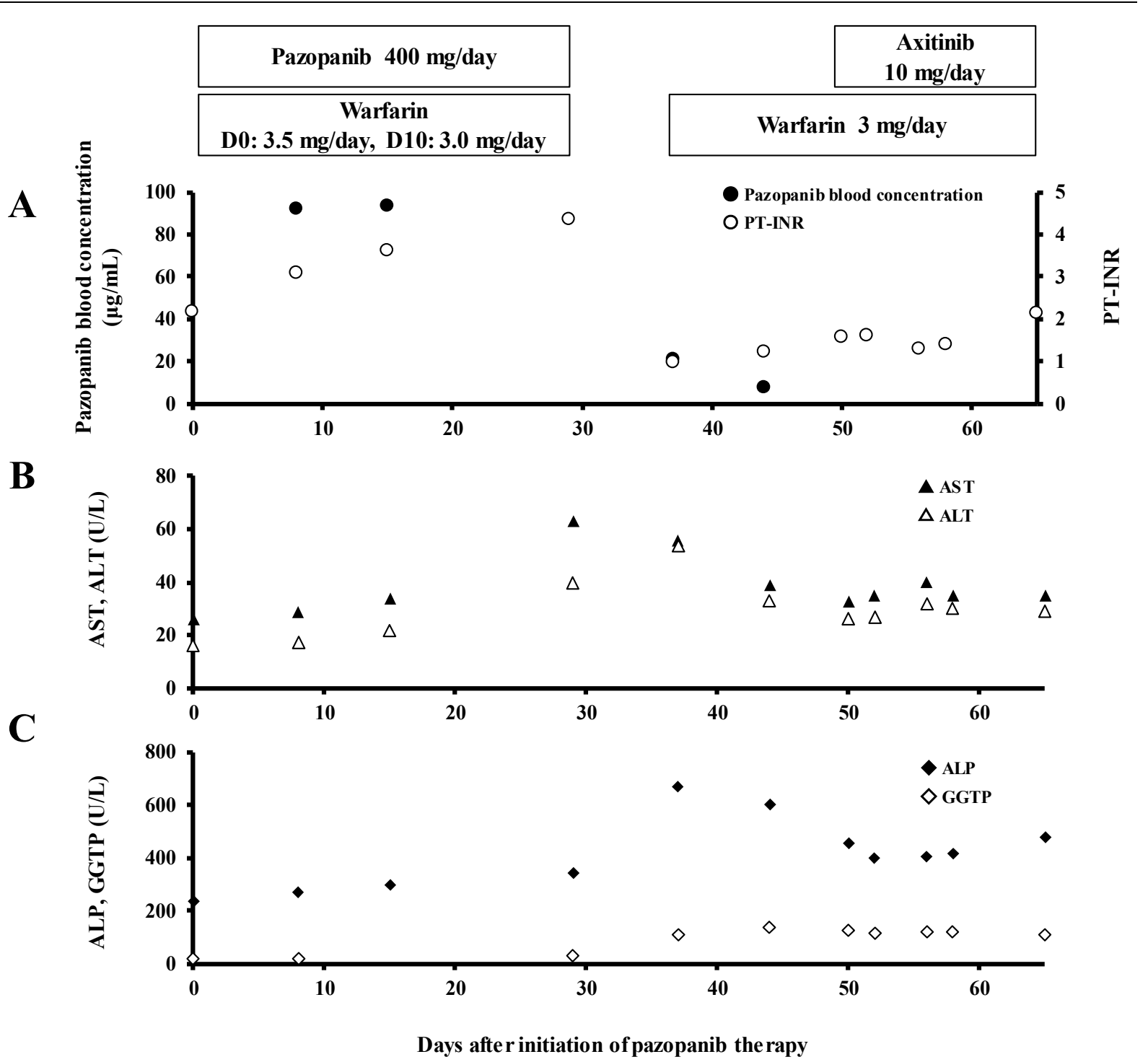

Figure 1. Changes in blood levels of pazopanib, PT-INR and liver function test, after combined use of pazopanib. ALP: alkaline phosphatase, ALT: alanine transaminase, AST: aspartate aminotransferase, GGTP: gamma-glutamyltransferase, PT-INR: prothrombin time-international normalized ratio

Therefore, it was difficult to explain away his abnormally high levels of pazopanib as the result of the absorption process. Pazopanib is mainly metabolized by CYP3A4 and, to a lesser extent, by CYP1A2 $(11,13,17)$. A potent CYP3A4 inhibitor, such as ketoconazole, increases blood levels of pazopanib (11). However, the patient was not taking potent CYP3A4 inhibitor drugs, and was not consuming grapefruit or its juices, which have known CYP3A4 inhibitory action (17). Although the patient was taking pranlukast, which has an inhibitory effect on CYP3A4, no significant effect is observed at the clinical dose (22). Pazopanib is a substrate for ATP-binding Cassette Sub-family B Member 1 (ABCB1) and ATP-binding cassette super-family $\mathrm{G}$ member 2 (ABCG2), two excretion transporters $(17,23)$, but none of his concomitant medications have been reported to act on excretion transporters and increase pazopanib levels. A recent report on the effect of genetic polymorphisms on pazopanib $\mathrm{PK}$ found that a CYP3A4 polymorphism can delay the excretion of pazopanib (24). However, as stated earlier, no genetic testing was performed. Thus, the reason for the abnormally high levels of pazopanib could not be clarified (even through a consideration of the metabolic process). We conclude that TDM would be useful for pazopanib because of the large inter-individual variation.

The observed elevation of PT-INR in this case is also difficult to explain clearly. A previous in vitro study showed that pazopanib had no effect on CYP2C9, a main metabolic enzyme of warfarin; 
thus, pazopanib does not affect the pharmacokinetics of warfarin in clinical patients (13). Nonetheless, since the patient's pazopanib concentrations were abnormally high, pazopanib may have increased the blood level of warfarin and enhanced its effects through some unresolved mechanism. Warfarin is known to have a high protein binding rate (97-99\%). However, unbound warfarin levels have been observed to increase due to competition for protein binding sites with a tyrosine kinase inhibitor, gefitinib, with a similar high protein binding rate (99\%), leading to the extension of PT-INR $(25,26)$. Pazopanib also has a high protein binding rate (greater than 99\%) (27), and the patient's high concentrations of pazopanib may have increased free warfarin and caused PT-INR prolongation. Moreover, these reports suggest that PT-INR may have increased due to gefitinib-induced liver dysfunction $(25,26)$. Interestingly, our patient also had liver dysfunction as a result of pazopanib therapy. The liver dysfunction may reduce the metabolic capacity of warfarin in the liver and reduce the production of coagulation factors, resulting in elevated PT-INR $(25,26)$. As a final consideration, vitamin $\mathrm{K}$ in the diet is known to antagonize the action of warfarin (28), so it is possible that the adverse effects of pazopanib may have reduced vitamin $\mathrm{K}$ intake, resulting in increased warfarin action. The patient was complaining of gustatory disorders, and although there was no apparent reduction in food during hospitalization, there may have been a reduction in food consumption during his time as an outpatient.

The levels of pazopanib in the patient's blood were high from the beginning and may be indicative of liver dysfunction and increased PT-INR. Although some patients with heart disease have been excluded from trials of pazopanib (2), pazopanib may also be used in patients receiving anticoagulant therapy (under similar circumstances to this case). In such high-risk patients, TDM of pazopanib is considered particularly useful. In the future, it may be possible to provide more accurate personalized therapy through TDM of pazopanib performed together with a screen for genetic polymorphisms on genes such as UGT1A1 and CYP.

\section{CONCLUSION}

This case shows that a patient with abnormally high pazopanib levels that was also taking warfarin experienced an elevated PT-INR. It appears that patients with high pazopanib levels may be at risk of drug interactions not previously identified such as warfarin. It is reasonable to postulate that other drug interactions could occur in patients with high pazopanib levels with drugs that are normally cleared hepatically or are highly protein bound. TDM monitoring, in addition to the recommended monitoring for pazopanib hepatotoxicity, may help identify patients at risk for these types of drug interactions. For patients receiving concomitant pazopanib and warfarin, close monitoring of PTINR is warranted.

\section{CONFLICT OF INTEREST}

The authors declare that have no competing interests.

\section{ACKNOWLEDGMENTS}

Measuring plasma concentration of pazopanib was supported by JSPS KAKENHI Grant Number $16 \mathrm{H} 00518$ (ST).

\section{ABBREVIATIONS}

ABCB1: ATP-binding cassette sub-family B Member 1

ABCG2: ATP-binding cassette super-family G member 2

ALP: alkaline phosphatase

ALT: alanine transaminase

AST: aspartate aminotransferase

CYP: cytochrome P450

GGTP: gamma-glutamyltransferase

PK/PD: pharmacokinetics/pharmacodynamics

PPI: Proton pump inhibitor

PT-INR: prothrombin time-international normalized ratio

RCC: renal cell carcinoma

TDM: therapeutic drug monitoring

UGT: uridine diphosphate glucuronosyltransferase

\section{REFERENCES}

1. Van Der Graaf WT, Blay J-Y, Chawla SP, Kim D-W, Bui-Nguyen B, Casali PG, Schöffski P, Aglietta M, Staddon AP, Beppu Y, Le Cesne A, Gelderblom H, Judson IR, Araki N, Ouali M, Marreaud S, Hodge R, Dewji MR, Coens C, Demetri GD, Fletcher CD, Dei Tos AP and Hohenberger P. Pazopanib for metastatic soft-tissue sarcoma (PALETTE): a randomised, double-blind, placebo-controlled phase 3 trial. Lancet. 2012; 379:1879-1886.

2. Motzer RJ, Hutson TE, Cella D, Reeves J, Hawkins R, Guo J, Nathan P, Staehler M, De Souza P, Merchan JR, Boleti E, Fife K, Jin J, Jones R, Uemura H, De Giorgi U, Harmenberg U, Wang J, Sternberg CN, Deen K, McCann L, Hackshaw MD, Crescenzo 
R, Pandite LN and Choueiri TK. Pazopanib versus sunitinib in metastatic renal-cell carcinoma. $\mathrm{N}$ Engl $\mathrm{J}$ Med. 2013; 369:722-731.

3. Gao B, Yeap S, Clements A, Balakrishnar B, Wong $\mathrm{M}$ and Gurney H. Evidence for therapeutic drug monitoring of targeted anticancer therapies. J Clin Oncol. 2012; 30:4017-25.

4. Widmer N, Bardin C, Chatelut E, Paci A, Beijnen J, Leveque D, Veal G and Astier A. Review of therapeutic drug monitoring of anticancer drugs part two--targeted therapies. Eur J Cancer. 2014; 50:2020-36.

5. Lankheet NAG, Desar IME, Mulder SF, Burger DM, Kweekel DM, Van Herpen CML, Van Der Graaf WTA and Van Erp NP. Optimizing the dose in cancer patients treated with imatinib, sunitinib and pazopanib. Br J Clin Pharmacol. 2017; 83: 21952204.

6. Suttle AB, Ball HA, Molimard M, Hutson TE, Carpenter C, Rajagopalan D, Lin Y, Swann S, Amado R and Pandite L. Relationships between pazopanib exposure and clinical safety and efficacy in patients with advanced renal cell carcinoma. $\mathrm{Br} \mathrm{J}$ Cancer. 2014; 111:1909-16.

7. Verheijen RB, Beijnen JH, Schellens JHM, Huitema ADR and Steeghs N. Clinical pharmacokinetics and pharmacodynamics of pazopanib: Towards optimized dosing. Clin Pharmacokinet. 2017; 56:987-997.

8. Noda S, Yoshida T, Hira D, Murai R, Tomita K, Tsuru T, Kageyama S, Kawauchi A, Ikeda Y, Morita S-Y and Terada T. Exploratory investigation of target pazopanib concentration range for patients with renal cell carcinoma. Clin Genitourin Cancer. 2019; 17:e306-e313.

9. Da Silva F, Thomas-Schoemann A, Huillard O, Goldwasser F and Blanchet B. Benefit of therapeutic drug monitoring to disclose pharmacokinetic interaction between sunitinib and calcium channel blocker. Ann Oncol. 2016;27:1651-2.

10. Takasaki S, Yamaguchi H, Kawasaki Y, Kikuchi M, Tanaka M, Ito A and Mano N. Long-term relationship between everolimus blood concentration and clinical outcomes in Japanese patients with metastatic renal cell carcinoma: a prospective study. JPHCS. 2019; 5:6.

11. Tan AR, Gibbon DG, Stein MN, Lindquist D, Edenfield JW, Martin JC, Gregory C, Suttle AB, Tada H, Botbyl J and Stephenson JJ. Effects of ketoconazole and esomeprazole on the pharmacokinetics of pazopanib in patients with solid tumors. Cancer Chemother Pharmacol. 2013; 71:1635-1643.

12. Van Leeuwen RWF, Van Gelder T, Mathijssen RHJ and Jansman FGA. Drug-drug interactions with tyrosine-kinase inhibitors: a clinical perspective. 2014; 15:e315-e326.

13. Goh BC, Reddy NJ, Dandamudi UB, Laubscher KH, Peckham T, Hodge JP, Suttle AB, Arumugham T, Xu Y, Xu CF, Lager J, Dar MM and Lewis LD. An evaluation of the drug interaction potential of pazopanib, an oral vascular endothelial growth factor receptor tyrosine kinase inhibitor, using a modified Cooperstown $5+1$ cocktail in patients with advanced solid tumors. Clin Pharmacol Ther. 2010; 88:652659.

14. Takasaki S, Tanaka M, Kikuchi M, Maekawa M, Kawasaki Y, Ito A, Arai Y, Yamaguchi H and Mano N. Simultaneous analysis of oral anticancer drugs for renal cell carcinoma in human plasma using liquid chromatography/electrospray ionization tandem mass spectrometry. Biomed Chromatogr. 2018; 32:e4184.

15. Xu C-F, Reck BH, Goodman VL, Xue Z, Huang L, Barnes MR, Koshy B, Spraggs CF, Mooser VE, Cardon LR and Pandite LN. Association of the hemochromatosis gene with pazopanib-induced transaminase elevation in renal cell carcinoma. J Hepatol. 2011; 54:1237-1243.

16. Motzer RJ, Johnson T, Choueiri TK, Deen KC, Xue $\mathrm{Z}$, Pandite $\mathrm{LN}$, Carpenter $\mathrm{C}$ and $\mathrm{Xu} \mathrm{CF}$. Hyperbilirubinemia in pazopanib- or sunitinibtreated patients in COMPARZ is associated with UGT1A1 polymorphisms广. Ann Oncol. 2013; 24:2927-2928.

17. Thorn CF, Sharma MR, Altman RB and Klein TE. PharmGKB summary: pazopanib pathway, pharmacokinetics. Pharmacogenet Genomics. 2017; 27:307-312.

18. Henriksen JN, Bøttger P, Hermansen CK, Ladefoged SA, Nissen PH, Hamilton-Dutoit S, Fink TL and Donskov F. Pazopanib-induced liver toxicity in patients with metastatic renal cell carcinoma: Effect of UGT1A1 polymorphism on pazopanib dose reduction, safety, and patient outcomes. Clin Genitourin Cancer. 2019. [Epub ahead of print]

19. Hurwitz HI, Dowlati A, Saini S, Savage S, Suttle AB, Gibson DM, Hodge JP, Merkle EM and Pandite L. Phase I trial of pazopanib in patients with advanced cancer. Clin Cancer Res. 2009; 15:4220-4227.

20. De Wit D, Van Erp NP, Den Hartigh J, Wolterbeek $\mathrm{R}$, Den Hollander-Van Deursen M, Labots $M$, Guchelaar H-J, Verheul HM and Gelderblom H. Therapeutic drug monitoring to individualize the dosing of pazopanib. Ther Drug Monit. 2015; 37:331-338.

21. Heath EI, Chiorean EG, Sweeney CJ, Hodge JP, Lager JJ, Forman K, Malburg L, Arumugham T, Dar MM, Suttle AB, Gainer SD and Lorusso P. A phase I study of the pharmacokinetic and safety profiles of oral pazopanib with a high-fat or low-fat meal in patients with advanced solid tumors. Clin Pharmacol Ther. 2010; 88:818-823.

22. Yoneda K, Matsumoto I, Sutoh F, Higashi R, Nunoya K-I, Nakade S, Miyata Y and Ogawa M. In Vitro Metabolism and inhibitory effects of pranlukast in human liver microsomes. Biol Pharm Bull. 2009;32: 688-693.

23. D'Cunha R, Bae S, Murry DJ and An G. TKI combination therapy: strategy to enhance dasatinib 
uptake by inhibiting Pgp- and BCRP-mediated efflux. Biopharm Drug Dispos. 2016; 37:397-408.

24. Bins S, Huitema ADR, Laven P, Bouazzaoui SE, Yu $H$, Van Erp N, Van Herpen C, Hamberg P, Gelderblom H, Steeghs N, Sleijfer S, Van Schaik RHN, Mathijssen RHJ and Koolen SLW. Impact of CYP3A $4 * 22$ on pazopanib pharmacokinetics in cancer patients. Clin Pharmacokinet. 2019; 58:651658.

25. Onoda S, Mitsufuji H, Yanase N, Ryuge S, Kato E, Wada M, Ishii K, Hagiri S, Yamamoto M, Yokoba M, Yanaihara T, Kuboto M, Takada N, Katagiri M, Abe T, Tanaka N, Kobayashi H and Masuda N. Drug interaction between gefitinib and warfarin. Jpn J Clin Oncol. 2005; 35:478-482.

26. Arai S, Mitsufuji H, Nishii Y, Onoda S, Ryuge S, Wada M, Katono K, Iwasaki M, Takakura A, Otani
S, Yamamoto M, Yanaihara T, Yokoba M, Kubota M, Katagiri M, Fukui T, Kobayashi H, Yanase N, Hataishi R and Masuda N. Effect of gefitinib on warfarin antithrombotic activity. Int $\mathrm{J}$ Clin Oncol. 2009; 14:332-336.

27. Imbs D-C, Paludetto M-N, Négrier S, Powell H, Lafont T, White-Koning M, Chatelut $\mathrm{E}$ and Thomas F. Determination of unbound fraction of pazopanib in vitro and in cancer patients reveals albumin as the main binding site. Invest New Drugs. 2016; 34:4148.

28. Konishi H, Eguchi Y, Fujii M, Saotome T, Sasaki T, Takahashi K, Sudo M, Morii H, Minouchi T and Yamaji A. Unusual hypersensitivity to warfarin in a critically ill patient. J Clin Pharm Ther. 2004;29: 485490 